\title{
DJ Culture in the Commercial Sydney Dance Music Scene
}

\author{
ED MONTANO \\ MACQUARIE UNIVERSITY (SYDNEY, AU)
}

\begin{abstract}
The development of contemporary, post-disco dance music and its associated culture, as representative of a (supposedly) underground, radical subculture, has been given extensive consideration within popular music studies. Significantly less attention has been given to the commercial, mainstream manifestations of this music. Therefore, this article examines the contemporary commercial dance music scene in Sydney, Australia, incorporating an analytical framework that revolves mainly around the work of DJs and the commercial scene they operate within. The ideas, opinions and interpretations of a selection of local DJs and other music industry practitioners who work in Sydney are central to the article's analysis of DJ culture within the city and of, more specifically, DJ self-understandings with respect to choices of records and in relation to the twin imperatives of entertainment and education.
\end{abstract}

\section{Keywords}

Sydney, DJs, programming, mainstream, clubbers

The arguments and observations contained within this article are based on ethnographic research I conducted in the Sydney dance music scene between 2002 and 2006. In addition to the requisite nights out clubbing, this research involved qualitative interviews with twenty-one people (DJs, journalists and promoters) conducted over a period between September 2004 and October 2005. All interviews were conducted "one-on-one", as opposed to in groups, and took place in locations such as bars, coffee shops, and respondents' homes (Weber 1999: 321). Furthermore, between September 2002 and December 2004, I was also a participant-observer, working at the Sydney-based specialist dance music store Central Station Records, and it was here I made contact with most of my interviewees, either directly, in the sense that they were customers of the store and so I came into regular contact with them, or indirectly through networks of contacts I managed to establish during my work at the store. While ethnographic research of this nature is not without problems (Thornton 1995: 105-107), I believe this was the best methodology to employ for this particular project, and as Brennan-Horley notes, "what is clear is that detailed ethnographic research is required to understand the workforce and commercial dimensions of dance music culture" (2007: 126). 
In using the terms "dance music" and "dance culture", I am referring to the "commercial", DJ-played music that one can hear in such Sydney clubs as Home, The ArtHouse, Slip Inn, and Tank, and at various bars, pubs, festivals and events within the city area. The article is intended to complement analysis that has previously been conducted on Sydney, and Australian, dance music culture (examples being Murphie and Scheer 1992; Homan 1998; Gibson and Pagan 2000; Brookman 2001; Luckman 2002; Slavin 2004; Brennan-Horley 2007). More generally, the article is intended to contribute to the growing literature on DJ culture around the world (examples being Fikentscher 1991, 2000; Klasco and Michael 1992; Langlois 1992; Rietveld 1997, 1998; Haslam 1997, 2001; Poschardt 1998; Reynolds 1998; Brewster and Broughton 2000; Gerard 2004; Farrugia and Swiss 2005).

\section{DJs and Sydney}

While the emphasis and importance that is placed on the possession of technical skills, such as beat-mixing and operating particular types of equipment (turntables, CD players, laptop computers), varies from DJ to DJ, the one constant and essential requirement for any DJ to be successful is an ability to select and sequence music in such a way that excites and interests the crowd. At the very centre of any DJ set is the interaction that occurs between the DJ and the clubbers on the dance floor, and the success of a dance event depends ultimately on the extent to which the DJ is able to develop and sustain this interaction. While a DJ presides over a dance floor, selecting the music and steering the flow of the event, this selection is determined by the reactions of the crowd, and a non-responsive crowd suggests a lack of engagement with the DJ's choice of music.

An issue of tension in the Sydney dance scene involves the performances of international DJs, and how these performances impact upon the scene as a local entity. It is clear that developments in the structure of the dance party scene in Sydney (with the establishment of large, annual parties and festival-like events that are staged at locations such as parks and other open public spaces, and are held during the day, such as Field Day, Parklife, Harbourlife, Future Music, Global Gathering, and Good Vibrations) have had an impact on the way clubbers perceive the relevance of international DJs. From a marketing perspective, these DJs serve to draw and attract people to the parties, and this has been interpreted by those within the scene in two contrasting ways. One is in a positive sense, in that these DJs help to educate the scene with new music and to broaden the global perspective of the scene's participants. In contrast to this, there is the negative argument that suggests these DJs, and the emphasis that clubbers place on them, create a DJ hierarchy of skill and ability, with the local DJs being consigned to the lower reaches of this hierarchy. It is an obvious fallacy to suggest that all international DJs are more skilful and more capable DJs than their local counterparts, and yet this is a perspective that is deeply imbedded within the very fabric of the Sydney scene. This stems, I would suggest, from the way the Sydney dance scene has its roots in an imported culture, in that, with an emphasis on imported vinyl, on imported music, on imported sounds, and on imported styles, comes an emphasis on imported DJs. With the centrality of the British, European, and American scenes to global dance culture, it follows that the key DJs from these scenes will be elevated to a position of significance by clubbers around the world. As Murphie and Scheer suggest, "house music in Australia is about constructing identities using borrowed or translated signifiers" (1992: 183). Similar notions of importing and borrowing have 
informed debates concerning the country's popular music in general, for as Hayward notes, "whatever its achievements, Australian popular music has been principally derived from imported models" (1992: 6).

This emphasis on overseas developments relates to the notion of "cultural cringe" that has permeated Australian culture and society. With the country's geographical isolation supposedly generating a degree of cultural isolation, "cultural cringe" involves the perception of locally-produced creative work as inferior to anything that originates outside of the country. Sydney DJ John Wall acknowledges the notion as a reason for the emphasis that participants in Sydney's dance music scene place on international DJs:

... people talk about cultural cringe, and it's very real. It's not as bad as it was when I was young, but nevertheless, because we are a long way away... people kind of assume that overseas dance culture is probably better, or bigger, or more sophisticated, or whatever, and that therefore the DJs are more skilful, it's more competitive, more music is available there, and so on and so on and so on...1

Ultimately, it is impossible to ignore the influence that international dance culture has had on the formation and development of the Sydney dance scene, and as Luckman points out,

... the wider popularisation in Australia of dance music and events in the early 1990s was fuelled, and hence participant's [sic] expectations and styles informed, in large part by the European, especially British, experience. Whether it was through fashion magazines, the growing celebrity status of overseas DJs, the accessibility at a recorded level of overseas material, or people's own travel abroad, the mythic ethos of the increasingly mainstream British scene loomed large over many Australian's [sic] consumer expectations. (2001: 6364; see also Brennan-Horley 2007: 124-125)

To lend such emphasis to DJs from outside of the scene does, however, obscure the important role the local DJs have in shaping and sustaining local dance culture. While the concept of "international DJs" emphasises the way dance culture exists on a global scale, it is important to note that it is the workings, happenings and events at the local level that give shape and structure to global dance culture. For this reason, the following discussion explores in greater detail the way local Sydney DJs interpret their profession, and works through some of the issues that shape and define the DJ's role. Specific focus is placed on local DJs, and what they perceive their responsibilities to be as a DJ, and there is discussion of the multiple roles of the DJ. Consideration is given to the way DJs approach their sets, what they play in these sets, the extent to which these sets are planned or spontaneous, and the tension that exists between the DJ's role as an entertainer and the DJ's role as an educator.

\section{The DJ set}

An issue worth noting in discussing the role of the DJ is the concern DJs give to the progression of an entire night, as opposed to solely their own set, in that a DJ will select their tracks in regard to their place within the night's DJ line-up and the time at which they are playing. Certain tracks suit certain points in the night, and as the comments of DJs show, in structuring their performances consideration is given not just to the content of their own sets, but also to the other DJs that will be playing on 
the same line-up. Thus, for example, a DJ who is scheduled to play at the beginning of the night has the role and responsibility to "warm up" the dance floor, which will be achieved through a balanced set of tracks that, on occasions, may send dancers into some degree of joyous frenzy, but on the whole, this particular role is about setting and establishing the mood.

As the term infers, "warming up" involves exactly that, in the sense that it is the role of the first one or two DJs to draw people on to the dance floor and warm them up for the headlining DJ. As a result, the "warm-up DJ" has to, at least in theory, restrain themselves from playing too many "anthems" or "big tracks", the task of which is usually performed by the main DJ, whose responsibility it is to "peak" the night, to create a sense of excitement, and "to prompt as strong as possible a response from the floor at least once during the evening" (Fikentscher 2000: 41). This is an issue acknowledged by Sydney DJ Trent Rackus when he states:

Programming is very important to me in a night; you've got to have it so each DJ complements the next... the vibe of the night should be built around each DJ working towards the next one and giving it that flow, and creating the energy via that ${ }^{2}$

Discussing how he approaches the planning and structuring of a set, Sydney DJ John Devecchis explains how, to maintain the flow and momentum of a night, it is important that the DJ is familiar with the styles of music that the DJs either side of them in the line-up will be playing:

If I don't know what a DJ before me or after me plays, I find out. I played in Brisbane recently at Family nightclub, and I phoned the promoter and asked him what the guy before me played. He basically told me that he played a little bit more pumped-up than I do, so I was like, right, the first thing I need to do when I get there is ask this guy if he'll pitch it down for his last three tracks, and I did, and it worked. For the guy after me, I was told he played quite vocal, so I made sure towards the end of my set I played three vocal tracks. You can mess a night up by changing the pitch or the style in one record, you can lose the floor, just like that. ${ }^{3}$

Thus, to ensure the success of a club night or dance event, the DJ has to familiarise themselves with the styles of the other DJs that will be working around them. The logics of dance culture dictate that coherency, flow and momentum must be maintained, and any rupture in this flow can serve to negatively affect the atmosphere within the club.

\section{Big tunes and little tunes}

Within club culture, a certain tension exists between the extent to which DJs are expected to play popular, well-known tracks, which typically generates an excited response from the dance floor, and the extent to which DJs should pursue a more challenging, and less explicitly commercial, path by playing tracks that are less familiar to clubbers. In discussing their opinions regarding the extent to which popular, "anthem" tracks should be played during the course of a set, DJs raise such variable and subjectively interpreted notions as "selling out" and "compromise of artistic integrity", making it difficult to draw out a common and shared approach to this aspect of DJ culture. The playing of too many "big tunes" in close sequence or throughout the course of one's set, what Rietveld refers to as "resorting to a kind of populism" (1998: 114), in- 
vites criticisms not only of a lack of experimentation, but also of a selfishness to promote one's own set at the expense of the following DJ's, in that if the warm-up DJ peaks the night too early, through playing a selection of some of the most popular tracks of the moment, there is nowhere else for the following DJ to "take" the night, which can disrupt the "flow" and "progression" of the night as a whole.

Given that the playing of popular tracks typically creates a sense of excitement within a crowd, to play such tracks during the initial stages of a night contradicts the ideologies of DJ practice that dictate that a crowd should not be peaked too soon. Citing a specific example, John Devecchis describes the difference between the role of the warm-up DJ and the role of the main DJ in playing certain tracks, and the way the warm-up DJ should, ideally, sacrifice the playing of certain tracks to avoid peaking the night too early:

You know the track "So Much Love To Give'? I saw one of the warm-up DJs at Home nightclub once, I won't mention his name, about two years ago when the track was massive, he warmed up for an international, and he was doing a good job, and as his last track before the international came in, he played "So Much Love To Give". I've never in my life questioned a DJ doing something before as much as I did that. He played the biggest tune of the moment as the very last track before an international came on. He peaked the crowd to the biggest they were going to get peaked all night, just as this poor international was coming on to play. It was the most unprofessional thing I've ever seen in my life... it was stupid. What's the point of booking an international if your warm-up DJ is going to outdo him? The job of a warm-up DJ is to get the crowd warmed up, get a groove, and get people on the dance floor. The ones who try to steal the limelight shouldn't be warming up for internationals, basically.

The exact content of a DJ's set is thus determined not only by their own personal taste in music, but also by the time at which they are scheduled to play during the course of a night. While the way in which this is interpreted will vary from DJ to DJ, discussion of the issue reflects how there are certain unwritten rules of DJing, rules that may be ignored on occasions, but on the whole, rules that help to maintain the musical flow and progression of a night.

\section{Planning versus spontaneity}

The DJ "set" typically lasts for between one to four hours, although as Fikentscher observes, a DJ's allotted time can "vary from 'guest spots' which can be as short as one or two hours, to marathon shifts that can last in excess of twelve hours" (2000: 84). During this set, through a specific selection of music, the DJ constantly alters the mood of their crowd, creating peaks and troughs, Spring describing how, "typically, a set begins softly and builds to an intense peak, then mellows out to bring the dancers down and signal the set's end" (2004: 50). These "peaks" represent moments when the DJ works up a particular intensity in their crowd through the playing of certain tracks, which may incorporate some adjustment of sound through, for example, a cutting out, and then a reintroduction, of a bass line or a vocal line. In reference to these dance floor peaks, Fikentscher notes how "both DJs and dancers are aware of the significance of the moments, as the ultimate manifestation of the communication linking the booth with the floor" (2000: 41).

It is through this work of the DJ that the records played transcend their commodity status as simply purchased recordings, in the sense that, as Langlois explains, 
"they are actively "performed" by the DJ himself, allowing spontaneity, surprise and creativity" (1992: 236), while Brookman describes the centrality of the DJ set to the clubbing experience and to the consumption of music that occurs within the clubbing environment, with the DJ producing a "continuous flow of music, often feeding off the response of the audience in choosing the tracks to play" (2001:19) (see also Klasco and Michael 1992: 61). In reference to the skills required for mixing, Thornton labels DJs "turntable musicians", suggesting that they fashion entirely new music out of their "raw material" of records (1995: 63). Théberge transfers this notion of musicality on to the equipment and technology used by DJs, suggesting that the skills and techniques developed by DJs have "transformed the turntable, a quintessentially reproductive device, into a productive one; a musical instrument of the first order" (2001: 15; author's italics). ${ }^{6}$

In responding to the mood of the crowd (Langlois 1992: 236), DJs need to be able to improvise and work spontaneously, and it is in this sense that DJ sets become performances, perhaps even more so than rock and pop concerts. A band or singer will often follow the structure of a set list, but it is extremely rare for a DJ to approach a set with a predetermined playing order, and indeed, such practice is frowned upon within DJ culture, and seen as contradicting the very notion of spontaneity that underpins DJing. As Sydney DJ Goodwill explains in regard to his own DJing:

None of it is predetermined. There's probably [been] twice in the ten years I've been DJing [when] I've specifically mixed two records together because it sounded good the night before. I hate that stuff. There are DJs out there who play [like that], especially international DJs that play the same set everywhere they DJ. I've noticed it lots of times where I've been travelling and I've seen the same international [DJ] playing three cities in a week, and they play the same set... that's just cheating, it's like sending your twin brother into work for you?

DJing is thus predicated on the immediacy of responding to the various different reactions of clubbers when they hear particular tracks. This dictates that a dance music event is a unique and unrepeatable happening, grounded very much in the moment in which it occurs, although as Goodwill highlights above, not all DJs work according to this principle.

The inherent spontaneity of a dance music event dictates that a significant degree of pre-planning is ultimately a pointless exercise, in that a DJ cannot predict exactly how a crowd will react to a particular track. This is not to say, however, that a DJ goes to perform a set without giving some prior consideration to the records they will play, for as John Devecchis explains, the exact style one chooses to focus on during a set is determined by the styles played by the other DJs on the line-up, and the venue at which one is playing:

[For example] I played at Sounds On Sunday (a weekly dance event held at the Greenwood Hotel in North Sydney, which typically runs from 2pm until 10pm) and warmed up for Jim Baron from Crazy Penis. Now I know that Jim Baron plays quite slow because I've seen him before, so I thought obviously I'm not going to play any big tunes, I'm warming up for an international, and I don't want to pump it too hard. I knew it was going to be a hard set because he plays with the pitch really far down... so I had to plan my set. I practised for four hours, I pulled out every track that I thought I wanted to play, put them in my box, along with a few tracks I knew worked at Sounds [On Sunday] from playing there... Now I've got an idea of what I'm going to play, but you don't always stick 
to it, you don't have an idea what you're going to play track for track, you just know these tracks are all kind of similar, and these next tracks all kind of lead on to them so I can put them together, and the next tracks lead on to them, and maybe pick out one every four or one every five and play them. That's how I generally structure my set, but it depends on who I'm playing before or after... You have to have an idea, but you can't plan?

Every DJ has to ensure there is a flow and coherency to the set, and thus, a DJ will, through the music played, vary the mood at several different points throughout the set, as Sydney DJ Paul Goodyear highlights when he describes his own approach to DJing:

For my sets, I always warm up, I never go in and "bang it", I always kind of start off at a mellower pace, pick it up to a peak, maybe drop it back down a little bit... [It depends] on the gig where I'm working at, but that's predominantly how I work... You have to cater for the crowd where you are playing. I always walk in and gauge the crowd?

Thus, most DJ sets can be described as spontaneous creations that are very much tied to the moment in which they are experienced, despite the fact that some degree of preplanning is most likely to have been arranged. It is important, however, not to overemphasise this notion of spontaneity, for a set is predetermined simply by the fact that a DJ can only take so much music to a particular performance. As Sydney DJ Alan Thompson highlights, all DJs predetermine their sets through the music that they decide to take with them to a gig, while he also describes the processes that can determine what music he takes with him and what music he plays:

There's a great myth about that. Many DJs will say to you, "No, I don't know what I'm going to play before I go into a club". Yes, you don't know what you're going to play, but you've got a hundred records in your box, so you've already decided what you are going to play... I might not necessarily know what order I'm going to play them in, but I've already obviously predetermined what I'm going to play by putting those one hundred records in the box, and how that works is, for me anyway, from front to back, my newest record is at the front, my oldest record is at the back, and then every week I might add one or two records, or I'll think, "I've been playing that for ages now, I'll take that out", and that's how my box works. Any DJ that says, "I have no idea what I'm going to do" is an absolute liar... it's in what order you are going to play them [that you don't know]... If I've played on a Friday night, and I've mixed three records together and they've worked really, really, really well, I'll play those three records in that row the next night, there's no reason why I can't do that at another club. ${ }^{10}$

\section{The DJ as consumer}

In purchasing music in much the same way as listeners and general consumers, the role of the DJ involves consuming music. At the same time, presenting that music to an audience, the DJ is "making a product - the performance of the music contained in that record" (Brewster and Broughton 2000: 21), or rather, as Malbon prefers to see it, "while the music is usually produced elsewhere, the DJs reproduce it through the use of technology" (1999: 82; author's italics).

Brookman notes that the role of the DJ as consumer is of relevance "since they are ultimately responsible for the purchase of music which is later consumed collectively by clubbers" (2001: 20), and thus, the DJ acts as a "cultural gatekeeper", or "cultural broker" (Fikentscher 2000: 12), selecting music made by other DJs and produc- 
ers, and presenting it to the wider clubbing public. Théberge suggests that we can "consider the art of the deejay as founded, initially, upon a type of consumer knowledge - a knowledge of musical style based in judgement and connoisseurship" (2001: 15), while Negus describes how DJs are "key taste makers and consumers" (1996: 63).

As such, clubbers actually experience "consumption" as practised for them. The process of consuming the records as a buyer is performed for clubbers, and is "indicative of the experiential component of consumption for participants in dance cultures" (Brookman 2001: 20).

\section{The DJ as educator versus the DJ as entertainer}

Alongside this consumption/production axis, the DJ also acts as both a performer, in that it is their responsibility to entertain the crowd in the club, and a promoter, playing new records when no one in the crowd may have heard them before (Frith 2001: 41). This dual role is acknowledged by Brewster and Broughton when they describe how, in their work, a DJ is "entertaining an audience and at the same time urging [this audience] to go out and buy something - the records that [the DJ] uses for [their] performance" (2000: 21). As Haslam suggests, a key skill of DJing is,

... obviously not just to drop the popular, well-known songs at the right part of the night, but to pick the right new releases, track down the obscurer tunes and newest imports, get hold of next month's big tune this month. (1997: 169)

When discussing how he perceives the role of the DJ, Goodwill acknowledges the balance that has to be achieved in the work of the commercial house music DJ between the playing of popular tracks and the playing of more obscure, lesser-known tracks:

The DJ is definitely there to entertain, that's my whole job... I feel a little bit of my role is to expose more of an interesting side to what's out there, I always try mix records together that people won't think I'll put together, and that's how I've gotten a bit of a name for myself, I think, is for not sticking to one style in a set... I think my role is to entertain, like any DJ, but I definitely put a large focus, personally, on breaking a new sound every time I DJ, or a new style, or a record that's a bit different and challenging the listener a little bit. ${ }^{11}$

Trent Rackus takes a similar approach towards his DJing, describing a specific example of a club in Sydney at which he used to play to highlight the balance he believes a DJ should try to attain between entertaining and educating:

I'd go to Gas thinking I'm going to play [certain records] tonight, and I'm really going to try to stick to the programme, but I'd get there, and the DJ before me had been playing big records, so you try [to] pull it back and play something less commercial, and you start to lose the crowd, and you don't want to be playing to no one. At the end of the day, you're employed by these venues to entertain the audience, and I think you've got a duty to them, when you're charging them good money, to put on a performance, but it also comes down to what you can withstand yourself... there are certain records I could never, ever play, and I cringe when I hear other DJs play them.12 
As Rackus goes on to explain, those DJs that choose to pursue a commercial path can serve to undermine the educational approach that some DJs try to take with their music:

I was playing at Homebar on Saturday night and I finished up at $1.30 \mathrm{am}$, and I was listening to what they were playing in the main room [at Home], and it was diabolical. I heard three tracks in a row - Lee-Cabrera's "Shake It", Starsailor's "Four To The Floor", and Freestylers' "Push Up" - these are three of the most commercial records that I'd be almost embarrassed to play in a two-hour set, yet these people were just belting them out one after another. This is why people don't become educated, and you find it harder to then go into a club and play cool music because people just don't get it... not every other DJ that is playing alongside of you, that's not their goal to educate people.13

For Paul Goodyear, maintaining a balance between entertaining and educating is a central part of the process of establishing, and maintaining, a connection with the crowd on the dance floor, as he explains while discussing the role of the DJ:

For me it's always been a two-way street. I like to educate, but I also love to play for the crowd too. I'm not one of these snobby DJs that won't play a Madonna track or a Kylie track. If that's going to help my night work much better... if I give them something, then they're going to be a lot more, I guess, open-minded, and let me be able to play brand new, cutting-edge stuff, and if it means playing a Madonna track, or whatever, to actually achieve that, then I'm very happy to do that. ${ }^{14}$

Through the responses outlined above, it can be seen how certain approaches to DJing have been ascribed a particular relevance and purpose. Educating a crowd has become linked to the playing of new music and to the musical tastes of the DJ, while entertaining is associated more with catering to the desires of a crowd and subsequent compromise on the part of the DJ.

With its quick turnover of music, fashions and styles, dance music culture is very much based on contemporary happenings, with constant attention being given to new music, and with a "strong emphasis upon the "here and now" (Malbon 1999: 182). It is the job of the DJ to actively seek out this new music, and to "educate" their audience with it, although the extent to which a DJ may be free to do this may be limited or constrained by the music policy of the club in which they play, as well as by the demands and expectations of their crowd, particularly if these are of a more commercial nature and orientation. The "underground" is generally seen as a place in which new music can be given greater exposure and in which this music can be presented to a compliant audience, whereas commercially-minded audiences are seen as comparatively less adventurous and less experimental in their choice of venue and music, and demand, on the whole, music that is familiar and recognisable. As Goodwill explains, while one part of the DJ's role is to educate their crowd with new music and new styles, playing in mainstream clubs can restrict the extent to which a DJ is free to do this:

I think that because I play at such overground venues, I probably teach a little bit less than people in the underground do... but then there's this whole other argument that I always think about... because I do get guilty about playing in big clubs, I think to myself "is this cheap and easy?", and then I do kind of calm myself down by thinking that what I do is teach people that are just learning about dance music something more, whereas I think a 
lot of the underground has to do with preaching to the converted. Everyone has a role and a responsibility to educate a little bit, it's just a matter of where you decide to do it. ${ }^{15}$

We can identify multiple roles for the DJ, such as promoter, educator and consumer of new music, but these are all subsumed under the DJ's main role as entertainer. The underlying principle that informs the everyday work of all DJs is to entertain. The DJ is paid to do a job, this job being to entertain a crowd, an essential part of which is playing the right type of music to actually attract this crowd into the club in the first place. If a DJ fails to draw a crowd, then they are failing in their role to entertain. Most DJs in the Sydney scene agree that there is a certain level of compromise involved in their work, and they mark a distinction between the local DJs who are there essentially to entertain, and therefore have to structure their sets in order to cater for commercial crowds, and the international DJs who attract clubbers purely through their status within dance culture, and who, while also having a responsibility to entertain, can incorporate more of an "educational" sensibility into their DJing through the playing of new and unfamiliar music. Sydney DJ Adam Jesse explains how, for local DJs like himself, the emphasis is on entertaining the crowd, and that it is only the internationally-known DJs who really have the opportunity to educate their audience, while he also acknowledges a perceived difference between the underground and the commercial scenes:

With DJs like us, we're doing what we can to get the gigs, whereas if you're at the level like Sasha, John Digweed or Paul Oakenfold, then you're educating. We need to push what sound works so we get more work... If you're booked to play a commercial nightclub, you can't go in there and try to educate people playing what you want to play, because the people that go to those clubs haven't gone there for that sort of reason. They've gone to the club to socialise. You have to keep it exciting and familiar, and play what people know, but you go to an underground club where people have gone to that club specifically to hear underground house music, you turn around and play a cheesy commercial set, it's wrong, they won't want to hear that, they've gone there for a specific reason..$^{16}$

\section{Conclusion}

It has been my aim to sketch an image of Sydney's dance scene through the words of the DJs involved in it. This dictates that some of the observations and interpretations are contextually specific, yet at the same time, the global nature of DJing, and indeed dance culture itself, means that these observations and interpretations can be drawn out and applied on a wider geographical scale, and thus, it is in this sense that this study transcends its specific focus on Sydney and can be seen as relevant to dance scenes elsewhere in the world. The content of DJ sets, planning versus spontaneity, warm-up spots, and the tension between the role of the DJ as an educator and the role of the DJ as an entertainer, are all issues that, when discussed by DJs who work within the Sydney scene, shed light on the workings that underpin dance culture in the city, yet they are also issues that inform dance scenes anywhere in the world.

The DJs in Sydney work within a scene that is constrained and limited by the comparatively small population of the city. This not only affects regularity of work, but it also dictates that dance culture in the city itself, and in Australia as a whole, lacks the industry infrastructure that has allowed scenes in Europe and America to develop as key sites of development and progression in dance music. This has subsequently meant that dance culture in Australia has developed with a reliance on the music, DJs, 
media and fashions of dance scenes overseas, and thus, DJs in Sydney play with music that is most typically foreign in origin. As a comparatively small scene, with a dependence on imported music, it can be argued that DJs in Sydney are more constrained by market demands, in that in order to maintain a level of popularity that generates sustained employment, they have to cater more to crowd expectations than DJs in other territories where there are more expansive and diverse dance scenes, and where it is financially possible to engage in experimentation. This is not to say that Sydney does not have a varied dance scene, but rather that the commercial concerns that are central to the scene and its continued existence do not accommodate the development of radical and experimental sub-scenes, and thus prevent the Sydney scene from developing in the same way as dance scenes in places such as Detroit, Chicago and Manchester have developed.

With these commercial concerns the emphasis on the DJ as an educator recedes in favour of a focus on the DJ as an entertainer. If large clubbing crowds are gained through the playing of particular, or rather popular, tracks, then it follows that DJs who play such tracks will be employed by clubs to cater to such crowds. If clubs wish to pursue such a commercial path even further, then club music policies will often be employed, which disrupts and constrains the freedom of choice a DJ may have in selecting their music. Yet it is largely idealistic to suggest that all DJs are free to play whatever music they want, and that all DJs can approach their work with the sole aim of educating a crowd with new and unfamiliar music. All DJs, regardless of their fame and stature within dance culture, have to keep in mind the expectations of their crowd during any one set.

As dance culture has developed into a mainstream phenomenon, the development of the concept of the superstar DJ has helped to position the DJ at the forefront of the culture, and it can be argued that this has had a direct impact on the Sydney dance scene, negatively affecting the role and significance of the local DJs. As DJs from Europe and America have been granted a degree of significance by those within global dance culture, DJs in Sydney have been reduced to a supporting role. As such, it is the international DJs who are permitted, by clubbing crowds in the city, a greater degree of freedom in the music that they play, and can thus take an approach that focuses more on new music, so that international DJs become ascribed a certain educational value by clubbers in the Sydney scene, often at the expense of the local DJs, who are subsequently seen more as entertainers, and less as promoters of new music.

Yet to reduce the workings of DJ culture in Sydney to such a simple dichotomy dismisses the very diversity that gives shape to the city's dance scene. As the different responses outlined in this article suggest, there are many distinct and divergent understandings of the nature of DJing work, dictating that it would be inappropriate to attempt to arrive at one defined and specific interpretation of DJ practice as it relates to the Sydney dance scene. Whether in regard to understandings of educating and entertaining, or approaches in planning a DJ set, every DJ has a different interpretation of the issues that shape and define their job. Thus, in interpreting and theorising DJ culture, a certain degree of fluidity has to be incorporated into the arguments and judgements that are subsequently formed. The approach each DJ takes to their work is defined by a number of factors, and these include the geographical location in which they are playing, the type of club at which they are playing, the order in the schedule they are playing, the type of crowd which they are playing to, the style of music they generally play, and their status and popularity within the scene in which they are playing. 


\section{References}

Brennan-Horley, Chris. 2007. "Work and Play: Vagaries Surrounding Contemporary Cultural Production in Sydney's Dance Music Culture". Media International Australia 123: 123-37.

Brewster, Bill and Frank Broughton. 2000. Last Night a DJ Saved My Life: The History of the Disc Jockey. London: Headline.

Brookman, Chris. 2001. 'Forever Young': Consumption and Evolving Neo-Tribes in the Sydney Rave Scene. BSc Thesis (Geosciences), University of Sydney.

Farrugia, Rebekah and Thomas Swiss. 2005. "Tracking the DJs: Vinyl Records, Work, and the Debate Over New Technologies”. Journal of Popular Music Studies 17(1): 30-44.

Fikentscher, Kai. 1991. "Supremely Clubbed, Devastatingly Dubbed: Some Observations on the Nature of Mixes on 12-inch Dance Singles". Tracking: Popular Music Studies 4(1): 9-15.

----. 2000. "You Better Work!" Underground Dance Music in New York City. Hanover: University Press of New England.

Frith, Simon. 2001. "The Popular Music Industry". In Simon Frith, Will Straw and John Street (eds), The Cambridge Companion to Pop and Rock, pp. 26-52. Cambridge: Cambridge University Press.

Gerard, Morgan. 2004. "Selecting Ritual: DJs, Dancers and Liminality in Underground Dance Music". In Graham St. John (ed), Rave Culture and Religion, pp. 167-84. London: Routledge

Gibson, Chris and Rebecca Pagan. 2000. "Rave Culture in Sydney, Australia: Mapping Youth Spaces in Media Discourse". http://www.snarl.org/youth/chrispagan2.pdf, accessed 15 August 2003.

Haslam, Dave. 1997. "DJ Culture”. In Steve Redhead, Derek Wynne and Justin O'Connor (eds), The Clubcultures Reader, pp. 150-61. Oxford: Blackwell.

----. 2001. Adventures on the Wheels of Steel: The Rise of the Superstar DJs. London: Fourth Estate.

Hayward, Philip (ed). 1992. From Pop to Punk to Postmodernism: Popular Music and Australian Culture from the 1960s to the 1990s. Sydney: Allen \& Unwin.

Homan, Shane. 1998. "After the Law". Perfect Beat 4(1): 56-83.

Klasco, Mike and Pamela Michael. 1992. "Crushing Grooves: The Art of Deejay Mixing”. Electronic Musician 8(10): 58-65.

Langlois, Tony. 1992. "Can You Feel It? DJs and House Music Culture in the UK". Popular Music 11(2): 229-38.

Luckman, Susan. 2001. "What Are They Raving On About?" Perfect Beat 5(2): 49-68.

----. 2002. Party People: Mapping Contemporary Dance Music Cultures in Australia. PhD Thesis, University of Queensland, Brisbane.

Malbon, Ben. 1999. Clubbing: Dancing, Ecstasy and Vitality. London: Routledge.

Murphie, Andrew and Edward Scheer. 1992. "Dance Parties: Capital, Culture and Simulation". In Philip Hayward (ed), From Pop to Punk to Postmodernism, pp. 172-84. Sydney: Allen \& Unwin.

Negus, Keith. 1996. Popular Music in Theory: An Introduction. Cambridge: Polity.

Poschardt, Ulf. 1998. DJ Culture. London: Quartet Books.

Reynolds, Simon. 1998. Energy Flash: A Journey Through Rave Music and Dance Culture. London: Picador.

Rietveld, Hillegonda. 1997. “The House Sound of Chicago". In Steve Redhead, Derek Wynne and Justin O'Connor (eds), The Clubcultures Reader, pp. 106-17. Oxford: Blackwell.

----. 1998. This Is Our House: House Music, Cultural Spaces and Technologies. Aldershot: Ashgate.

Slavin, Sean. 2004. "Drugs, Space, and Sociality in a Gay Nightclub in Sydney". Journal of Contemporary Ethnography 33(3): 265-95. 
Spring, Ken. 2004. "Behind the Rave: Structure and Agency in a Rave Scene". In Andy Bennett and Richard A. Peterson (eds), Music Scenes: Local, Translocal, and Virtual, pp. 48-63. Nashville: Vanderbilt University Press.

Théberge, Paul. 2001. "Plugged In': Technology and Popular Music". In Simon Frith, Will Straw and John Street (eds), The Cambridge Companion to Pop and Rock, pp. 3-25. Cambridge: Cambridge University Press.

Thornton, Sarah. 1995. Club Cultures: Music, Media and Subcultural Capital. Cambridge: Polity.

Weber, Timothy. 1999. "Raving in Toronto: Peace, Love, Unity and Respect in Transition". Journal of Youth Studies 2(3): 317-36.

\section{Author Biography}

Ed Montano has an MA in Popular Music Studies from the Institute of Popular Music at the University of Liverpool and a PhD on the commercial Sydney dance music scene from Macquarie University. He teaches on a popular music history course at Macquarie University, works in music retail, and writes for the Australian dance music website www.inthemix.com.au

\section{Notes}

1 John Wall, interview with the author (Sydney), 16 September 2005.

2 Trent Rackus, interview with the author (Sydney), 13 September 2004.

3 John Devecchis, interview with the author (Sydney), 24 September 2004.

$4 \quad$ "So Much Love To Give" was a hugely popular track in the Sydney dance scene during 2002 and 2003; credited to Together, it was composed by the two French producers DJ Falcon and Thomas Bangalter, and was initially released on the label Roule Records in 2002.

5 John Devecchis, interview with the author (Sydney), 24 September 2004.

6 See Fikentscher (2000: 35-42) and Langlois (1992) for detailed descriptions of the technical and practical skills involved in DJing and mixing.

7 Goodwill, interview with the author (Sydney), 8 September 2004.

8 John Devecchis, interview with the author (Sydney), 24 September 2004.

9 Paul Goodyear, interview with the author (Sydney), 11 May 2005.

10 Alan Thompson, interview with the author (Sydney), 23 June 2005.

11 Goodwill, interview with the author (Sydney), 8 September 2004.

12 Trent Rackus, interview with the author (Sydney), 27 September 2004.

13 Trent Rackus, interview with the author (Sydney), 27 September 2004.

14 Paul Goodyear, interview with the author (Sydney), 11 May 2005.

15 Goodwill, interview with the author (Sydney), 8 September 2004.

16 Adam Jesse, interview with the author (Sydney), 18 September 2004. 